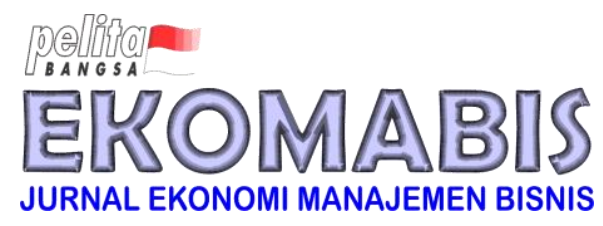

\title{
Keunggulan Bersaing : Identitas Merek, Inovasi Produk dan Orientasi Pasar Study UMKM Hijab di Kabupaten Bekasi
}

Submit: 11 Jul 2020; Review: 30 Aug 2020; Accepted: 06 Dec 2020； Publish: 07 Dec 2020

Junedi $^{1}$

\begin{abstract}
Building the brand identity of MSMEs seems to have a role in an effort to help create creative ideas. Product innovation has an important role in competitive advantage. Assessing market opportunities requires a large overall measurement and conditions of business competition, therefore to understand market conditions requires a market orientation in the business world. Competitive advantage seems to be a competitive arena for business actors, therefore business actors must always create new things in making their products.
\end{abstract}

Keywords: Brand Identity, Product Innovation, Market Orientation and Competitive Advantage.

JEL Codes:

\begin{abstract}
ABSTRAK
Membangun identitas merek UMKM tampaknya memiliki peran dalam sebuah usaha guna membantu untuk menciptakan ide kreatifitas. Inovasi produk mempunyai peran penting dalam keunggulan bersaing. Menilai peluang pasar membutuhkan pengukuran besar secara keseluruhan dan kondisi persaingan bisnis, oleh karena itu untuk memahami kondisi pasar perlu adanya orientasi pasar dalam dunia usaha. Keunggulan bersaing seolah menjadi ajang kompetisi bagi para pelaku usaha, oleh sebab itu para pelaku usaha harus selalu menciptakan hal-hal yang baru dalam membuat produknya.
\end{abstract}

Kata kunci: Identitas Merek (IM), Inovasi Produk (IP), Orientasi Pasar (OP) dan Keunggulan Bersaing (KB)

Kode JEL:

1 Universitas Pelita Bangsa; junedi@pelitabangsa.ac.id 


\section{Pendahuluan}

Fashion adalah fenomena yang dinamis karena sering mengalami perubahan tergantung pada konteks budaya, sosial, ekonomi, politik, estetika, tren mode, diadopsi atau tidak, dan akhirnya menghilang (Kim et al, 2014; Laura Nistor, 2017). Mengenakan hijab dalam bentuk inovatif, sebagian besar dengan menggabungkannya dengan model atau item fashion tertentu, adalah contoh untuk penyesuaian budaya. Berbicara tentang visual kelas melalui kerudung dengan mengenakannya cara-cara tertentu, tentang aspirasi etnis dan status mereka di Indonesia seperti pendidikan, karier, dll.

Bisnis hijab pada saat ini sedang berkembang luas dan banyak diminati oleh para pelaku usaha. Hijab adalah salah satu kebutuhan sandang bagi kaum wanita muslim di seluruh dunia. UMKM Hijab menunjukan perkembangan yang kian meluas dari tahun ke tahun.

Keunggulan bersaing adalah parameter kinerja perusahaan dalam pasar bersaing yang seolah menjadi ajang kompetisi bagi para pelaku usaha, pada dasarnya seorang pelanggan selalu menginginkan hal-hal yang baru demi mengikuti perkembangan zaman. Inovasi produk mempunyai peran penting dalam keunggulan bersaing, perkembangan zaman membuat aneka ragam konsumen dalam memilih suatu produk, yang akan mereka beli. Keunggulan bersaing pada dasarnya tumbuh dari nilai atau manfaat yang diciptakan oleh perusahaan, menciptakan produk yang sulit ditiru oleh pesaing, memiliki daya tahan keunikan produk yang berbeda dengan pasar lainnya dan bagi para pembelinya yang lebih dari biaya yang harus dikeluarkan untuk menciptakannya. Tahapan-tahapan ini dapat diuraikan sebagai pengenalan masalah, yaitu pelaku usaha menyadari bahwa adanya persaingan bisnis yang sangat ketat dan tidak bisa dihindari lagi. Maka segala upaya dan cara dilakukan untuk mengatasinya dilakukan. Diantaranya membuat produk yang tidak mudah ditiru, tidak mudah digantikan, membuat suasana kompetisi yang menciptakan nilai bagi suatu perusahaan dengan mengeksploitasi peluang (Banrey; 1991; Titin Suhaeni: 2018).

Dimensi merek sebagai organisasi mencerminkan karakteristik kunci UMKM yang menyarankan mereka untuk memiliki dan struktur, proses minimum yang ditetapkan dan kontrol dengan nilai bersama dan hubungan pribadi (Carson dan Cromie, 1990; Carrier, 1994). Pada waktu bersamaan, UMKM ternyata memiliki seperangkat keunikan nilai-nilai organisasi didorong oleh nilai-nilai pribadi dan visi pemilik merek. Inovasi produk merupakan produk atau jasa baru yang dipekenalkan ke pasar inovasi produk dikategorikan sebagi produk yang telah ada, penentuan kembali dan pengukuran biaya. Dalam mengukur adanya inovasi produk, UMKM bisa membuat suatu perluasan produk yang dalam hal ini merupakan produk yang masih familiar bagi organisasi baru lagi bisnis namun baru bagi pasar (Lukas dan Ferrel, 2000, Cynthia dan Hendra; 2014). 
Orientasi pasar adalah budaya organisasi yang paling efektif dan efisien dalam menciptakan perilaku yang diperlukan untuk menciptakan nilai superior bagi pelanggan untuk memberikan kinerja bisnis yang superior secara berkelanjutan. Orientasi pasar sebagai budaya organisasi yang paling efektif dalam menciptakan pelaku penting untuk menciptakan, nilai unggul bagi pembeli serta kinerja untuk pembeli serta kinerja dalam bisnis (Baker dan Sinkula, 2009; Naver dan Satler, 1990). Pembagian serta fungsi koordinasi yang baik dam memiliki rasa komitmen dalam melakukan kegiatan pemasaran. Orientasi pasar tidak hanya menjadi tanggung jawab dari fungsi pemasaran, tetapi partisipasi masingmasing departemen dalam tindak lanjut dari orientasi pasar, selain itu orientasi pasar berfokus pada pasar yang mencakup pelanggan dan faktor-faktor atau kekuatan pengruhnya.

Relatif sedikit studi yang berfokus secara spesifik mengenai penelitian merek UMKM. Secara khusus, topik membangun merek UMKM tampaknya memiliki sebagian besar dalam penelitian sampai saat ini. Secara implisit, telah diasumsikan dan merek organisasi besar tumbuh sama bahkan ketika konteks dan sumber dayanya sangat berbeda.

\section{Metodologi}

Penelitian ini merupakan penelitian deskriftif kuantitatif, metode yang berdasarkan pada filsafat positivisme, digunakan untuk meneliti pada populasi atau sampel tertentu menggunakan analisis regresi linier ganda. Sebagaimana kriteria analisis regresi linier ganda maka analisis dilakukan melalui tahapan uji instrumen, uji persyaratan analisis, uji model dan uji hipotesis. Pengumpulan data menggunakan instrument penelitian, analisis data bersifat kuantitatif/statistik dengan tujuan untuk menguji hipotesis yang telah ditetapkan (Sugiyono; 2014).

Penelitian ini dimaksudkan untuk mendapatkan gambaran dan keteranganketerangan mengenai pengaruh identitas merek, inovasi produk dan orientasi pasar terhadap keunggulan bersaing pada UMKM hijab di Kabupaten Bekasi. Penelitian ini dilakukan dengan pengamatan, wawancara dan survey langsung ke pelaku-pelaku UMKM pakaian hijab di Kabupaten Bekasi dengan melakukan uji analisis linier berganda serta uji hipotesis (uji t).

Uji instrumen melalui uji validitas reliabilitas. Uji validitas menggunakan nilai corected item correlation sedangkan uji reliabilitas menggunakan Cronbach Alpha. Uji persyaratan analisis yang digunakan adalah uji asumsi klasik yang terdiri dari normalitas, multikolinieritas, dan heteroskedastisitas. Normalitas dilakukan secara grafis (histogram), uji multikolinieritas menggunakan VIF,dan heteroskedastisitas secara grafis dengan scatter plot. Uji model digunakan untuk memastikan kelayakan model. Kelayakan model dilihat dari nilai R Square sedangkan pengujiannya dengan uji $\mathrm{F}$. 
Uji hipotesis menggunakan nilai koefisien regresi untuk menentukan arah pengaruh sedangkan pengujian dilakukan dengan uji-t. Koefisien regresi diperoleh dari persamaan regresi linier ganda unstandardized:

$\mathrm{Y}=\mathrm{a}+\mathrm{b} 1 \mathrm{X} 1+\mathrm{b} 2 \mathrm{X} 2+\mathrm{b} 3 \mathrm{X} 3$

\section{Hasil}

Data yang disajikan dalam indeks faktor, kemudian di analisis dengan menggunakan analisa regresi yang dilakukan dengan menggunakan program statistik SPSS. Analisis dilakukan dengan meregresi tiga variabel independen yaitu Identitas Merek (IM), Inovasi Produk (IP) dan Orientasi Pasar (OP) terhadap variabel Keunggulan Bersaing (KB), yang hasilnya sebagai berikut :

Tabel 1. Uji Hipotesis

Coefficients $^{\circledR}$

\begin{tabular}{cccccc}
\hline & \multicolumn{5}{c}{ Standardized } \\
Model & Unstandardized Coefficients & Coefficients & & \\
\cline { 2 - 4 } (Constant) & $\mathrm{B}$ & Std. Error & Beta & $t$ & Sig. \\
IM & .231 & 2.646 & & .843 & .407 \\
IP & .438 & .172 & .387 & 2.538 & .017 \\
OP & .321 & .139 & .413 & 2.310 & .029 \\
& .082 & .189 & .073 & .433 & .668 \\
\hline
\end{tabular}

a. Dependent Variable: $\mathrm{Y}$

Sumber: Data primer diolah (2017)

Model persamaan regresi linier ganda hasil analisis berdasar tabel diatas adalah sebagai berikut:

$\hat{Y}=2.231+0.438 \mathrm{IM}+0.321 \mathrm{IP}+0.082 \mathrm{OP}$

\section{Pembahasan}

Hipotesis pertama yang diajukan dalam penelitian ini bahwa Identitas Merek berpengaruh terhadap Keunggulan Bersaing. Analisis menghasilkan temuan bahwa nilai koefisien regresi Beban Kerja sebesar b1 $=0.438$ dengan nilai sig. $=$ 0,017 . Nilai Sig t untuk Identitas Merek lebih besar dari taraf uji penelitian $(0,017$ $<0,05)$ sehingga signifikan atau hipotesis diterima. Hal ini menunjukkan bahwa Identitas Merek berpengaruh dengan arah positif terhadap Keunggulan Bersaing.

Hipotesis kedua yang diajukan dalam penelitian ini bahwa Inovasi Produk berpengaruh terhadap Keunggulan Bersaing. Analisis menghasilkan temuan bahwa nilai koefisien regresi Kompensasi sebesar b2 $=0.321$ dengan nilai sig. $=0,029$. Nilai Sig $\mathrm{t}$ untuk Inovasi Produk lebih kecil dari taraf uji penelitian $(0,029$ $<0,05)$ sehingga signifikan atau hipotesis diterima. Hal ini menunjukkan bahwa 
Inovasi Produk berpengaruh dengan arah positif terhadap Keunggulan Bersaing.

Hipotesis ketiga yang diajukan dalam penelitian ini bahwa Orientasi Pasar tidak berpengaruh terhadap Keunggulan Bersaing. Analisis menghasilkan temuan bahwa nilai koefisien regresi Kompensasi sebesar b3 $=0.082$ dengan nilai sig. $=0,668$. Nilai Sig $t$ untuk Orientasi Pasar lebih besar dari taraf uji penelitian $(0,668$ $>0,05)$ sehingga signifikan atau hipotesis ditolak. Hal ini menunjukkan bahwa Orientasi Pasar tidak berpengaruh terhadap Keunggulan Bersaing.

\section{Kesimpulan}

Kesimpulan dari penelitian menghasilkan model persamaan regresi linier ganda $\hat{Y}=2.231+0.438 \mathrm{IM}+0.321 \mathrm{IP}+0.082 \mathrm{OP}$ dimana Identitas Merek, Inovasi Produk dan Orientasi Pasar mampu menjelaskan 75,08\% variabilitas Keunggulan Bersaing

Identitas Merek berpengaruh terhadap Keunggulan Bersaing. Artinya semakin unik dan menarik identitas merek yang dimiliki oleh UMKM maka semakin tinggi pula keunggulan UMKM dalam bersaing.

Inovasi Produk berpengaruh terhadap Keunggulan Bersaing. Artinya UMKM yang semakin inovatif terhadap produk yang dijual maka semakin tinggi pula keunggulan UMKM dalam persaingan.

Orientasi Pasar tidak berpengaruh terhadap Keunggulan Bersaing. Artinya bahwa penerapan orientasi pasar didalam mencari informasi pasar untuk menentukan strategi kedepannya tidak mempengaruhi keunggulan dalam bersaing. Dari kesimpulan ini, dapat dikatakan bahwa UMKM Hijab di Kabupaten Bekasi perlu focus terhadap identifikasi merek untuk membangkitkan nilai jual produk. Selain itu perlu juga untuk melakukan inovasi dari produk hijab tersebut karena tidak menutup kemungkinan bahwa pasar hijab di Kabupaten Bekasi ini adalah para kaum wanita muda yang mengutamakan style fashion yang kekinian dan menginginkan model yang selalu modern dan dinamis.

\section{Daftar Pustaka}

Nistor, Laura. (2017). Hijab(istas) - as Fashion Phenomenon. A Review. Acta Universitatis Sapientiae Social Analysis. 7. 10.1515/aussoc-2017-0004.

Sheen M, Aman Key Yekani H, Jordan TR (2018) Investigating the effect of wearing the hijab: Perception of facial attractiveness by Emirati Muslim women living in their native Muslim country. PLOS ONE 13(10): e0199537.

Bullock, K. (2018). Pious Fashion: How Muslim Women Dress: Elizabeth Bucar Cambridge, MA: Harvard University Press, 2017. 248 pages. American Journal of Islam and Society, 35(3), 87-90. 
Banrey, (2018). Pengaruh Strategi Inovasi Terhadap Keunggulan Bersaing Diindustri Kreatif (Studi Kasus UMKM Bidang Kerajinan Tangan Di Kota Bandung) Jurnal Riset Bisnis Dan Investasi vol. 4, no 1, April 2018 ISSN2460-8211

Baker dan Sinkula, (2009). The Influence Of Market Orientation and Product Innovation On The Competitive Advantage and Its Implication Toward Small and Medium Enterprises (UKM) Performace. Terbit di jurnal Internasional Journal Science And Engineering Invention volume 04, issue 08 agustus 2018 DOI:10.23958/ijsei/vol04-i08/0.

Idar et al, (2012) The Influence Of Market Orientation and Product Innovation On The Competitive Advantage and Its Implication Toward Small and Medium Enterprises (UKM) Performace. Terbit di jurnal Internasional Journal Science And Engineering Invention volume 04, issue 08 agustus 2018 DOI:10.23958/ijsei/vol04-i08/0.

Lumpkin dan Dess (1996). Pengaruh Orientasi Kewirausahaan, Inovasi Produk, dan Keunggulan Bersaing Terhadap Kinerja Pemasaran Usaha, Jurnal MBA, Vol.2 No.3

Lukas dan Ferrel (2000). The Effect of Market Orientation on product innovation, journal of academy of Marketing Science, 28 (2), 239-247.

McDaniel, (2002). Entrepreneurship and innovation: Economic Approach.M.E sharp,inc, New York

Never dan Satler, (1990).The Effect Of Maket Orientatoion On Competitive Advantages, Research Journal Of Business and Management, 2017, Vol:4 Issue 4

Porter, (1993). Anlisis faktor-faktor pengaruh inovasi produk yang berdampak pada keunggulan bersaing UMKM makanan dan minuman di wilayah harjamukti dikota Cirebon. Dalam jurnal logika, vol XVIII, NO, 3 DESEMBER 2016 p-ISSN: 1978-2560 e-ISSN : 2442-5176.

Wahyudin, (2015) The Influence Of Market Orientation and Product Innovation On The Competitive Advantage and Its Implication Toward Small and Medium Enterprises (UKM) Performace. Terbit di jurnal Internasional Journal Science And Engineering Invention volume 04, issue 08 agustus 2018 DOI:10.23958/ijsei/vol04-i08/0.

Hemsley-Brown, Jane \& Melewar, T.C. \& Nguyen, Bang \& Wilson, Elizabeth. (2016). Exploring brand identity, meaning, image, and reputation (BIMIR) in higher education: A special section. Journal of Business Research. 69. 10.1016/j.jbusres.2016.01.016.

Hemsley-Brown, Jane \& Melewar, T.C. \& Nguyen, Bang \& Wilson, Elizabeth. (2016). Exploring brand identity, meaning, image, and reputation (BIMIR) in higher education: A special section. Journal of Business Research. 69. 10.1016/j.jbusres.2016.01.016.

Centeno, Edgar \& Hart, Susan \& Dinnie, Keith. (2013). The five phases of SME brand-building. Journal of Brand Management. 20. 10.1057/bm.2012.49.

Sugiyono. (2014). Metode Penelitian Pendidikan Pendekatan Kuantitatif, Kualitatif, dan R\&D. Bandung: Alfabet. 